\title{
Shallow velocity structure and hidden faults of Kunming city region*
}

\author{
YU Geng-xin ${ }^{1), *}$ (于更新) LOU Hai ${ }^{2}$ (楼 海) WANG Chun-yong ${ }^{2)}$ (王椿铺) \\ FU Li-yun ${ }^{1)}$ (符力耘) ZHANG Jian-guo ${ }^{3)}$ (张建国) QIN Jia-zheng ${ }^{3)}$ (秦嘉政) \\ YANG Run-hai ${ }^{3)}$ (杨润海) LI Hai-ou ${ }^{4}$ (李海鸥)
}

1) Institute of Geology and Geophysics, Chinese Academy of Sciences, Beijing 100029, China

2) Institute of Geophysics, China Earthquake Administration, Beijing 100081, China

3) Earthquake Administration of Yunnan Province, Kunming 650224, China

4) Institute of Geology, China Earthquake Administration, Beijing 100029, China

\begin{abstract}
In order to image the 3-D velocity structure of its shallow crust in Kunming region, China, finite-difference seismic tomography is used to invert the seismic data selected carefully from six-shot data. The result lays a foundation for the discussion of the relationship between the obtained velocity structure and the hidden faults, and for the illumination of the depth extents of main active faults surrounding Kunming city. Puduhe-Xishan fault lies on the western margin of the Kunming basin and is just situated on the west edge of the low velocity anomaly zone found at all depth levels. This indicates that this fault is a borderline fault of the Kunming basin. It can be concluded that the fault dips eastwards with a steep angle and its depth extent is large. Puji-Hanjiacun fault and Heilongtan-Guandu fault play a role in controlling the low velocity anomaly zone in middle basin. The depth extents of the two faults are comparatively small, without traversing the interface of basin floor.
\end{abstract}

Key words: finite-difference; velocity structure; hidden fault; Puduhe-Xishan fault CLC number: P315.2 Document code: A

\section{Introduction}

According to the division of seismic belts, Kunming city is situated on N-S Puduhe moderate-strong seismic belt, just between famous N-S Xiaojiang strong seismic belt and Yimen moderate-strong seismic belt. In history, moderate-strong earthquakes of magnitude larger than $M_{\mathrm{W}} 6.0$ took place many times in above three seismic belts. The largest earthquakes are Luquan $M_{\mathrm{W}} 6.3$ earthquake in 1985, Songming $M_{\mathrm{W}} 8.0$ earthquake in 1833 about $30 \mathrm{~km}$ away from Kunming city and Wuding $M_{\mathrm{W}} 6.5$ earthquake in 1995, respectively. According to the fourth period division of Chinese seismic intensity, Kunming city is situated in VIII division (peak acceleration $\geq 2 \mathrm{~m} \cdot \mathrm{s}^{-2}$ ), a potential seismic focal zone with magnitude upper limit $M_{\mathrm{W}} 6.5$. Therefore, Kunming city being one of the few high seismic intensity provincial capital cities in China, it is of importance to take active fault detection around Kunming city.

\footnotetext{
Received 2008-04-01; accepted in revised form 2008-06-11.

Foundation item: Basic Scientific Research Program of Institute of Geology, China Earthquake Administration (DF-IGCEA-0608-2-8) and State Key Basic Research Development and Programming Project of China (2004CB418401).

^ Author for correspondence: y_g_xin@126.com
} 
In the period of the Tenth Five-year Plan, Earthquake Administration of Yunnan Province carried out an artificial seismic sounding in 2005, a part of city active fault detection project launched by China Earthquake Administration, to find out 3-D velocity structure in shallow crust and depth extents of the principal active faults around Kunming city, and then to provide detailed basis for the evaluation of earthquake risk of seismic active faults. In this paper, 3-D seismic velocity structure beneath Kunming city is obtained by using finite-difference seismic tomography for the data from the rectangle survey line around Kunming city shown in Figure 1. The relations between the velocity structure and the characteristics of active faults are also discussed.
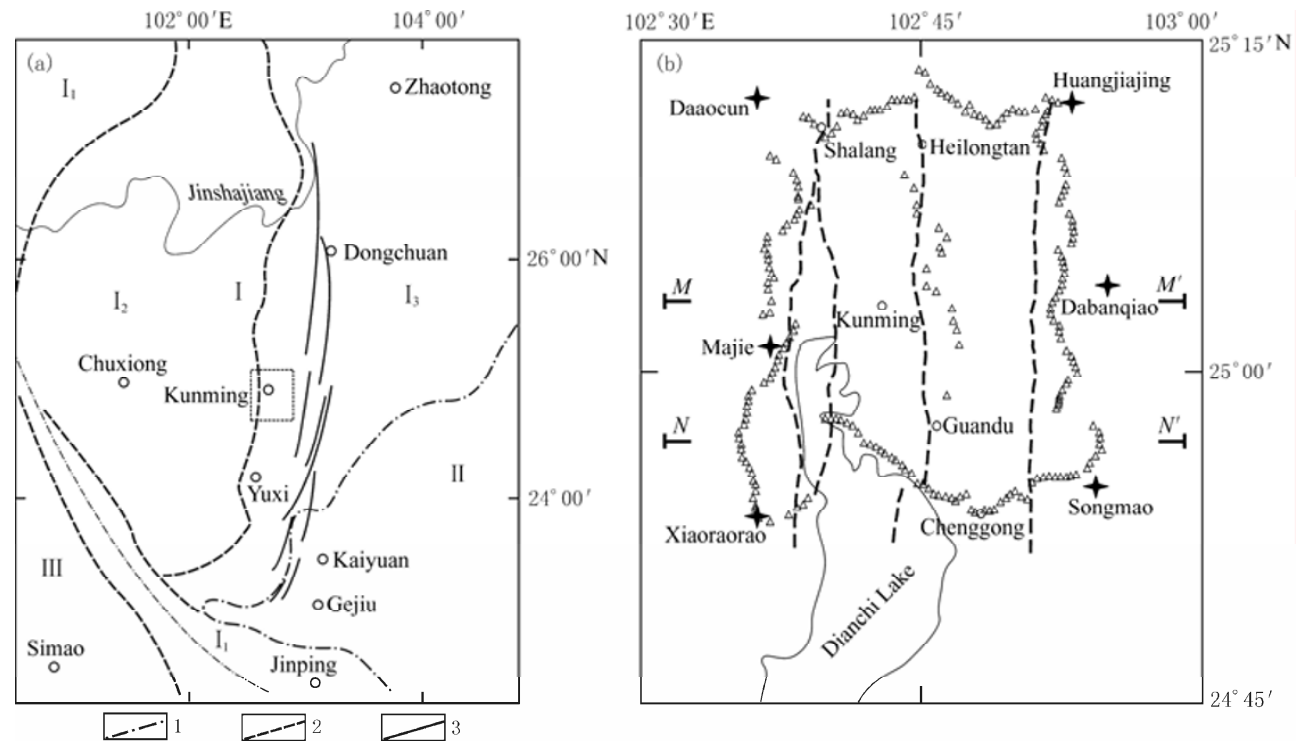

Figure 1 Division of regional geotectonic units (a) and distribution of receivers and faults in object area (b)

1. First-order geotectonic unit boundary; 2. Second-order geotectonic unit boundary; 3. Xiaojiang fault; I. Yangtze metaplatform; $\mathrm{I}_{1}$. Lijiang platformal margin fold belt; $\mathrm{I}_{2}$. Sichuan-Yunnan anteklise; $\mathrm{I}_{3}$. East Yunnan platform fold belt; II. South China fold system; III. Tanggula-Changdu-Lanping-Simao fold system; The quadri-stars mark shots; Open triangles denote stations; $M M^{\prime}$ and $N N^{\prime}$ stand for the tangential position of two longitudinal profiles; Four thick dash lines represent main hidden faults in object area. Figure 1a follows SONG et al (1998)

\section{Regional geologic setting and active faults in study region}

The city of Kunming is situated in northern Kunming basin of central Yunnan Plateau and surrounded by mountains to the west, north and east, and Dianchi Lake to the south. Kunming basin is a structural basin with complex geologic structure and is located at the southern tip of China North-South Structural Belt. As shown in Figure 1a (SONG et al, 1998), according to the geotectonic division, Kunming is situated on the dividing line of two second-order geotectonic units, Sichuan-Yunnan anteklise and East Yunnan platform fold belt in Yangtze metaplatform. In light of new structural division, Kunming situated in third-order new structure region of Sichuan-Yunnan fault-block upheaval region, is an important part of eastern Yunnan strong fault lake basin region in the background of regional new structural upheaval region.

Basal shape and the thickness of Quaternary cover vary largely across Kunming basin. Four principal active faults in study region control the formation and development of Kunming basin 
(JIANG et al, 2003), which are Puduhe-Xishan fault, Puji-Hanjiacun fault, Heilongtan-Guandu fault and Baiyi-Hengchong fault respectively from west to east. Most parts of them are hidden below surface except the parts on the edge of the basin and outside of the basin (Table 1).

Table 1 Basic information of main faults around Kunming city

\begin{tabular}{|c|c|c|c|c|c|c|}
\hline Fault name & $\begin{array}{l}\text { Attitude of } \\
\text { fault }\end{array}$ & Fault type & $\begin{array}{c}\text { Thickness of } \\
\text { Quaternary } \\
\text { cover/m }\end{array}$ & $\begin{array}{c}\text { Length in } \\
\text { target area } / \mathrm{km}\end{array}$ & $\begin{array}{c}\text { Length of } \\
\text { hidden part } / \mathrm{km}\end{array}$ & $\begin{array}{c}\text { Length of } \\
\text { uncovered part } / \mathrm{km}\end{array}$ \\
\hline Puduhe-Xishan & NNE & Normal slip & $\geq 500$ & 37 & 19 & 18 \\
\hline Puji-Hanjiacun & NNE & Normal slip & $\geq 500$ & 30 & 25 & 5 \\
\hline Heilongtan-Guandu & N-S & Normal slip & $\geq 250$ & 38 & 32 & 6 \\
\hline Baiyi-Hengchong & $\mathrm{N}-\mathrm{S}$ & Normal slip & $70 \sim 80$ & 37 & 22 & 15 \\
\hline
\end{tabular}

\section{Inversion of 3-D velocity structure}

\subsection{Method}

Finite-difference travel time algorithm was put forward and extended to 3-D by Vidale (1988; 1990). Hole and Zelt (1995) improved Vidale's algorithm by incorporation of head-wave operators and reverse propagation of travel time, which solved the computation problem of first arrival travel time in 3D media with large velocity contrasts. This method starts from eikonal equation, and divide the media into square grids. The first arrival travel times of all grids can be calculated at once by virtue of known travel times of shots, the average slowness of grids and the finite-difference formulae about known and unknown grids. And the computation time depends approximately linearly on the number of grid nodes and is independent of the number of receivers and almost independent of the velocity model. As a result, the finite-difference method is superior to ray tracing method under the conditions of complex 3-D media and multi-receivers. Therefore, this method has achieved more common usage (WANG et al, 1997; DUAN et al, 2002; BAI and WANG, 2003; ZHAO et al, 2004).

This research adopts the back projection inverse method put forward by Hole (1992). According to ray theory, ray is perpendicular to wavefront, so ray direction is just the gradient direction of time field. Then when we trace from receivers to shots along the gradient direction of time field, we can get the complete ray path. Without matrix calculation, this method has the advantage of a great saving of computation time and memory. For these grids passed by ray path, it distributed travel time residuals directly along the ray path and thus the slowness corrections can be acquired; for others, it smoothed the area which ray did not pass by with Laplace interpolation and then we can get the slowness corrections of all the inverse area. The slowness model is updated by the addition of the model perturbation and is then used as the new reference model for another linearized inversion. Iterations are stopped when some criterion indicates that the data have been satisfied (Hole, 1992).

\subsection{Seismic data}

Rectangle survey line encircles the Kunming city (Figure 1), and the lengths of its each side are about 25. Six shots with explosive charge $600 \mathrm{~kg}$ at each shot are set up in Dabanqiao, Majie, Huangjiajing, Daaocun, Xiaoraorao and Songmao, which are respectively situated in east, west, northeast, northwest, southwest and southeast of Kunming basin. There are 237 survey stations on the rectangle survey line with mean spacing of survey stations $400 \mathrm{~m}$. 
The first arrival Pg has the advantage of simple and definite phase discrimination (Figure 2). After preliminary data processing, 780 Pg travel time are picked from the valid records accounting for $55 \%$ of all 1418 seismic records, of which the record qualities of three shots Xiaoraorao, Songmao and Majie are relatively better (Table 2). 3-D and horizontal distributions of Pg seismic rays beneath Kunming city are shown in Figure 3.
Table 2 Statistics of effective records from each shot

\begin{tabular}{llccc}
\hline No. & Shot place & $\begin{array}{c}\text { Record } \\
\text { numbers }\end{array}$ & $\begin{array}{c}\text { Valid } \\
\text { record } \\
\text { numbers }\end{array}$ & Percentage \\
\hline 1 & Daaocun & 237 & 82 & $35 \%$ \\
2 & Huangjiajing & 235 & 97 & $41 \%$ \\
3 & Majie & 237 & 152 & $64 \%$ \\
4 & Dabanqiao & 235 & 132 & $56 \%$ \\
5 & Xiaoraorao & 237 & 163 & $69 \%$ \\
6 & Songmao & 237 & 154 & $65 \%$ \\
\hline
\end{tabular}

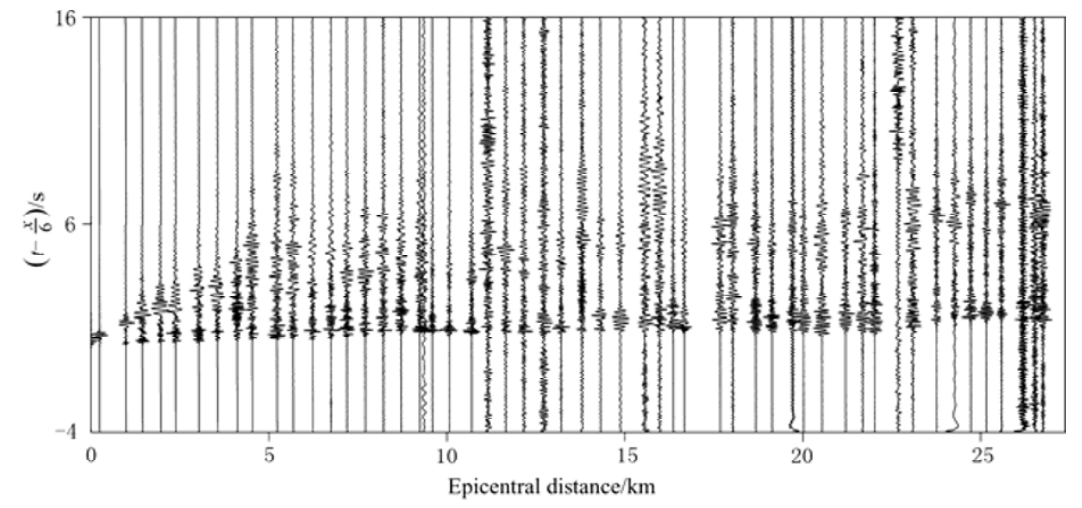

Figure 2 Reduced record section from Xiaoraorao shot
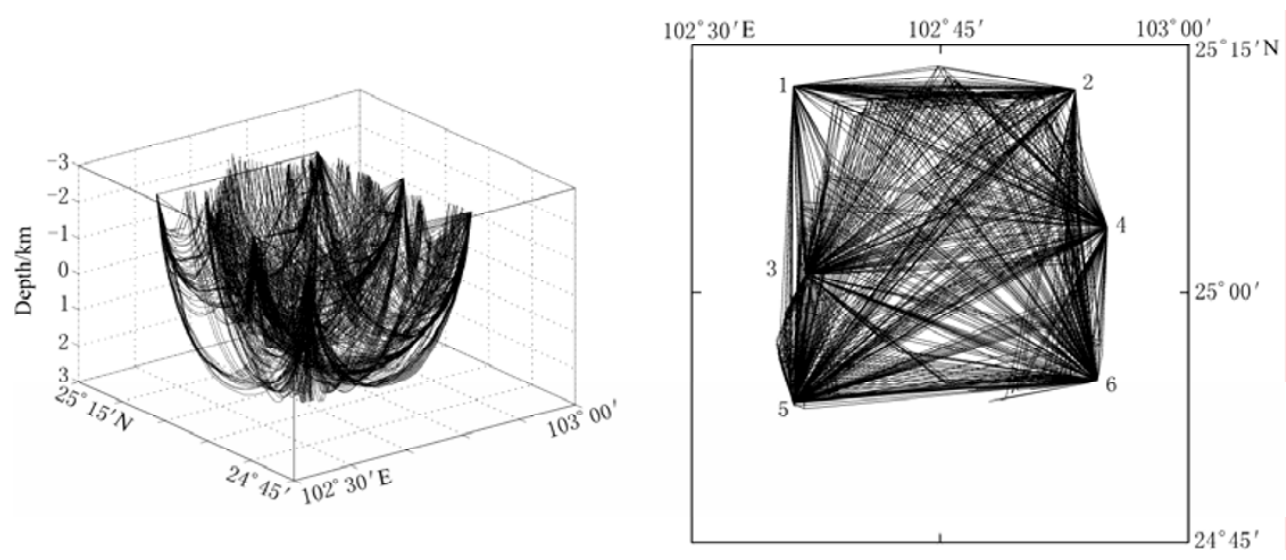

Figure 3 A 3D view and a plane view of seismic rays

\subsection{Model parameterization and resolution analysis}

In finite-difference tomography algorithm, the model is parameterized with 3-D cubic grids. According to the distribution region of rectangle survey line, the scale of velocity model is selected as $50 \mathrm{~km} \times 50 \mathrm{~km} \times 10 \mathrm{~km}$. A variable grid technique is also adopted (DUAN et al, 1999). The grid space is set up as $0.5 \mathrm{~km}$ for travel time computation and ray tracing to improve the accuracy of travel time field computed by finite-difference algorithm and the accuracy of theory ray; while the grid space is set up as $2 \mathrm{~km} \times 0.5 \mathrm{~km}$ when taking inversion computation. Initial 1-D velocity 
model is inferred from mean travel time curve of near shot travel time data near Kunming and also consults the related study results of east Yunnan crust velocity (HU et al, 1986).

According to the characteristics of ray distribution and the results of several tests, grid space in horizontal direction is set up as $2 \mathrm{~km}$ to test the inversion resolution. Inversion results from checkerboard resolution tests show that inversion resolutions change with the depth. Near the surface, inversion results in the vicinity of the stations are relative good. With the increase in inversion depth, central parts of the study region have relatively better inversion results. In view of ray distribution, seismic rays mainly center on the regions close to the stations when the penetrating depth of seismic rays is less than $1 \mathrm{~km}$ from the surface. Therefore, velocity distribution from tomography inversion results in shallow layers is reliable just in the regions close to stations. Seismic rays mostly pass through the regions beneath the basin when the penetrating depth of seismic rays is between $2 \mathrm{~km}$ and $3 \mathrm{~km}$. Thus velocity distributions in those depths are rather reliable.

\section{Results}

The inversion of finite-difference tomography requires four iterations. The iteration stops when the root-mean-square (RMS) travel time residual no longer continues to reduce. The initial RMS travel time residual is $0.35 \mathrm{~s}$, and the RMS travel time residual reduces to $0.09 \mathrm{~s}$ after four iterations. Resolution test results and ray distribution show that the velocity structure in shallow layers is reliable just in the regions close to stations. Velocity distribution in central section is relatively reliable in depth about $2 \mathrm{~km}$. Therefore, the velocity distributions just in depth $-1.0 \mathrm{~km}$ and $0 \mathrm{~km}$ are shown in Figures $4 \mathrm{a}$ and $4 \mathrm{~b}$.

In Figure 4a the distribution characters of high velocity regions in east, west and north of the study region and low velocity zones in central section and south of the study region are consistent with the geographic environment of Kunming city that is situated in north of Kunming basin and

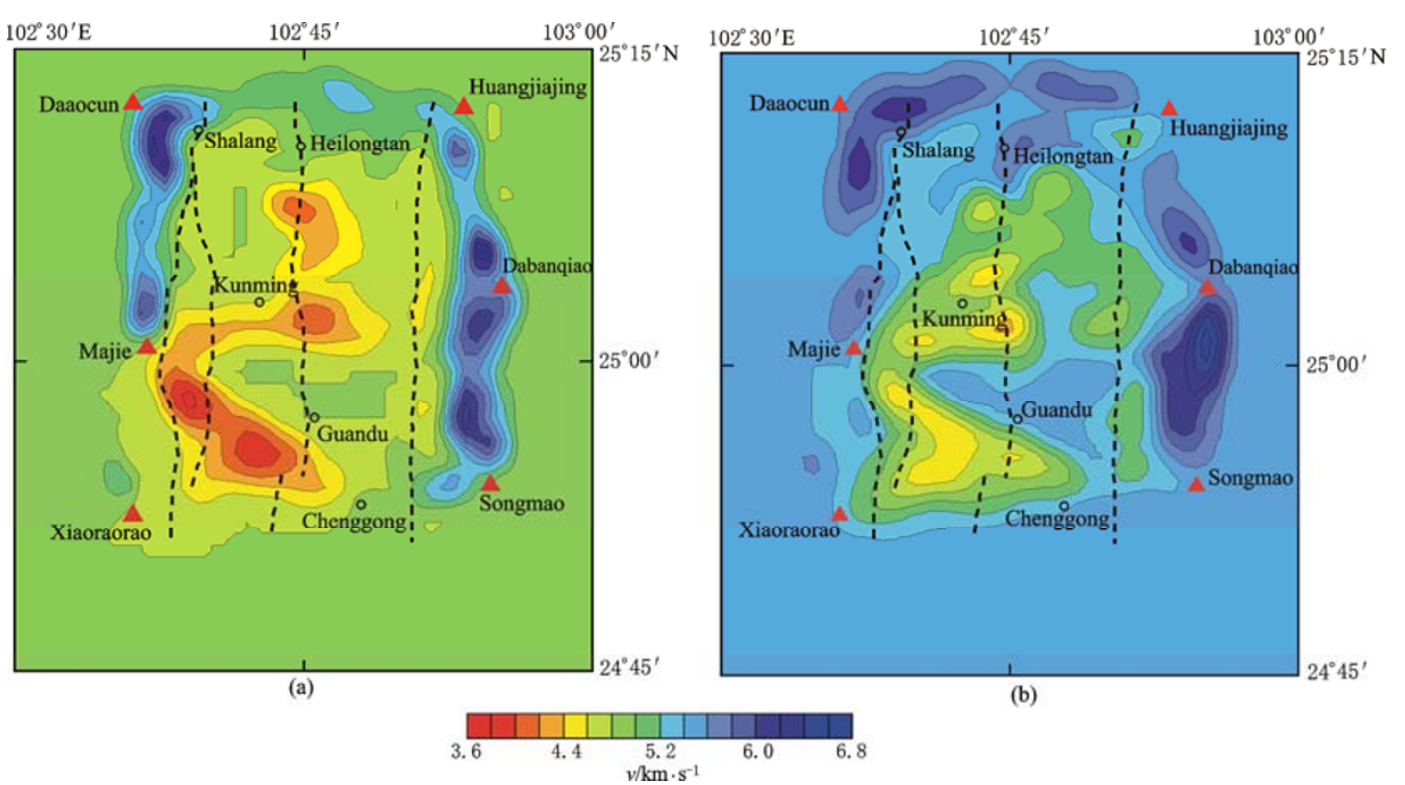

Figure 4 Velocity distribution at depth of $-1.0 \mathrm{~km}(\mathrm{a})$ and $0 \mathrm{~km} \mathrm{(b)}$

Red solid triangles represent shots; Four dash lines denote the hidden faults: Puduhe-Xishan fault, Puji-Hanjiacun fault, Heilongtan-Guandu fault and Baiyi-Hengchong fault, as seen from left to right on each map 
surrounded by mountains to the west, north and east, and Dianchi Lake to the south. The velocity distribution in Figure $4 \mathrm{~b}$ shows the heterogeneity of the structure in the interior of the basin. Mountain area in the east of rectangle survey line is a relatively gentle low velocity region, while velocity variation in the west of rectangle survey line is large. Several local low velocity anomalies exist in central section of the study region. Along south branch of rectangle survey line there is a WNW-ESE strike low velocity zone, the west tip of which connects with the low velocity zone in the central section. There is a wedge of normal velocity zone between low velocity zone in the central section and high velocity zone along the east branch of rectangle survey line. All those local low velocity anomalies are related to the basal structure of the basin and the variation in the thickness of the sedimentary layers deposited in different epochs. In Figures $4 \mathrm{a}$ and $4 \mathrm{~b}$ there is a normal velocity zone between the Majie shot and Xiaoraorao shot. However, its velocity is obviously less than that in mountain area. This phenomenon may be caused by the overthrust of the mountain area in the west of the Kunming basin partly to the west of the Dianchi Lake on the effect of the regional northwest tectonic stress.
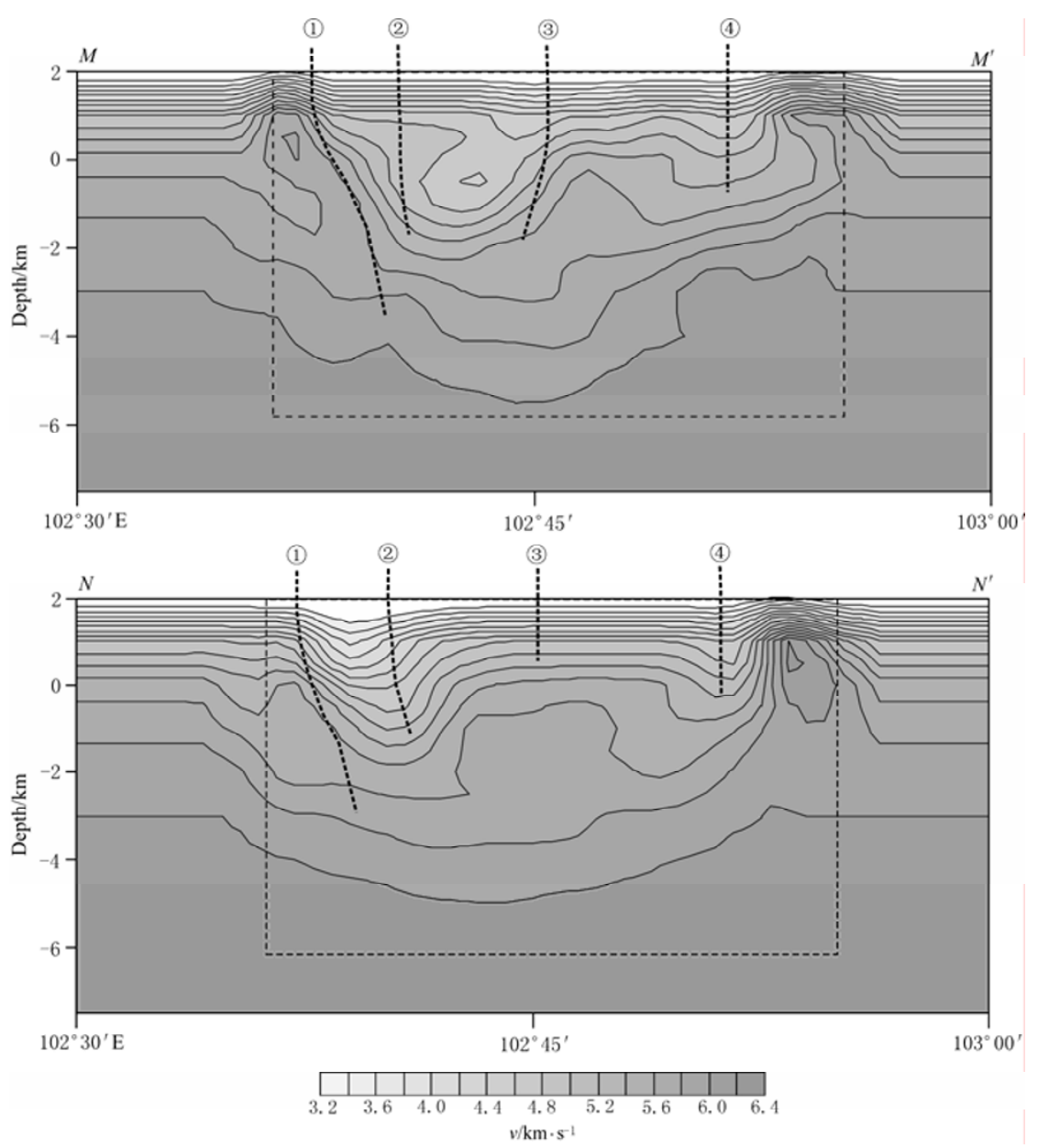

Figure 5 Longitudinal velocity distribution and extensional characters of deduced hidden faults Rectangle dash line frame denotes the region penetrated by seismic rays; Four thick dash lines represent hidden faults; From left to right on each map are Puduhe-Xishan fault, Puji-Hanjiacun fault, Heilongtan-Guandu fault and Baiyi-Hengchong fault, respectively 
Bayi-Hengchong fault is situated in the gentle low velocity zone in the east of the study region. There is no obvious velocity variation on both sides of Bayi-Hengchong fault. Comparatively, other three faults have significant relations with the velocity distribution. Puduhe-Xishan fault is situated on the west side of the basin and on the west boundary of low velocity anomaly of velocity distribution at different depths. This indicates that this fault is a boundary fault of Kunming basin. Based on the characters of velocity distribution, the extensions of main hidden faults shown in two longitudinal profiles (Figures $5 \mathrm{a}$ and $5 \mathrm{~b}$ ) are deduced. Puduhe-Xishan fault inclines to east at a steep dip angle with larger depth extent than that of Puji-Hanjiacun fault, Heilongtan-Guandu fault and Baiyi-Hengchong fault.

\section{Discussions and conclusions}

In combination with the surface distribution characters of main active faults, the extensions of the main hidden faults in study region are deduced according to the distribution characters of 3-D velocity structure in shallow layers of Kunming city obtained by using finite-difference tomography. The following are several conclusions.

1) The whole pattern of the velocity distribution with high velocity zone in east, west and north of the study region and low velocity zone in central section and south of the study region consists with the geographic environment of Kunming city situated in northern Kunming basin surrounded by mountains to the west, north and east, and Dianchi Lake to the south.

2) Puduhe-Xishan fault, Puji-Hanjiacun fault and Heilongtan-Guandu fault have significant relationship with the velocity distribution. Puduhe-Xishan fault is located at the west edge of the low velocity anomaly zone existing in the velocity distributions at different depths. This indicates that it is a boundary fault of the west side of the Kunming basin. Puji-Hanjiacun fault and Heilongtan-Guandu fault control the development of low velocity anomaly zone existing in the central section of the basin.

3) Baiyi-Hengchong fault is located in the gentle low velocity anomaly zone in the east of the study region and has no significant relationship with the velocity distribution for there is no clear velocity variation on both sides of the fault.

4) Four hidden faults have obvious differences in depth extent. Puduhe-Xishan fault has large depth extent, while the depth extents of Puji-Hanjiacun fault, Heilongtan-Guandu fault and Baiyi-Hengchong fault are comparatively small.

\section{References}

BAI Zhi-ming and WANG Chun-yong. 2003. Tomographic investigation of the upper crustal structure and seismotectonic environments in Yunnan Province [J]. Acta Seismologica Sinica, 16(2): 127-139.

DUAN Yong-hong, LAI Xiao-ling, ZHANG Xian-kang, et al. 1999. Finite-difference 2-D and 3-D seismic travel time velocity tomography [J]. North China Earthquake Sciences, 17(4): 53-60 (in Chinese).

DUAN Yong-hong, ZHANG Xian-kang, FANG Sheng-ming. 2002. Three-dimensional finite-difference tomography of velocity structure of the upper crustal in North China [J]. Chinese J Geophys, 45(3): 362-369 (in Chinese).

Hole J A and Zelt B C. 1995. 3-D finite-difference reflection travel times [J]. Geophys J Int, 121: 427-434.

Hole J A. 1992. Nonlinear high-resolution three-dimensional seismic travel time tomography [J]. J Geophys Res, 97: 6553-6 562.

HU Hong-xiang, LU Han-xing, WANG Chun-yong, et al. 1986. Crustal structure in western of Yunnan Province by explosion experiment [J]. Chinese J Geophys, 29: 133-144 (in Chinese).

JIANG Chao-song, ZHOU Rui-qi, WANG Shao-jing. 2003. Forming model and evolution of Kunming basin [J]. Journal of Seismological Research, 26(2): 172-175 (in Chinese).

SONG Fang-min, WANG Yi-peng, YU Wei-xian, et al. 1998. The Active Xiaojiang Fault Zone [M]. Beijing: Seismological Press: 1-2. (in Chinese)

Vidale J E. 1988. Finite-difference calculation of travel times [J]. Bull Seism Soc Amer, 78: 2 062-2 076.

Vidale J E. 1990. Finite-difference calculation of travel times in three dimensions [J]. Geophysics, 55: 521-526.

WANG Chun-yong, ZHANG Xian-kang, DING Zhi-feng, et al. 1997. Finite-difference tomography of upper crustal structure in Dabieshan orogenic belt [J]. Chinese J Geophys, 40(4): 495-501 (in Chinese).

ZHAO Jun-meng, WANG Qing-chen, DUAN Yong-hong, et al. 2004. A finite difference study on the basement structure beneath the Tianshan Orogen [J]. Science in China (Series D), 47(Suppl): 16-23. 